\title{
STEWARDS IN AN “ODD” KINGDOM. PERFORMANCE AND REMUNERATION OF THE BOARDS OF DIRECTORS OF NHS FOUNDATION TRUSTS.
}

Running Head: Performance-related pay on NHS Boards

Authors: Javier García-Lacalle, Sonia Royo and Ana Yetano (Universidad de Zaragoza)

\begin{abstract}
Performance measures and rewards are becoming commonplace in public sector organizations. This paper studies the implementation of performance-related pay (PRP) mechanisms in the boards of directors of the Foundation Trusts (FTs) of the National Health Service (NHS) in England and analyzes whether their remuneration is linked to organizational performance using qualitative and quantitative analyses (structural equation model). FTs operate in a favorable context for implementing PRP to remunerate executive directors. Our results show that many FTs have not implemented PRP and hardly any report having payed bonuses. However, most of them disclose that they carry out some kind of performance appraisal. These results indicate both reluctance to and difficulties in adopting PRP in public sector entities. Results also suggest that executive directors of NHS FTs are stewards in an "odd" kingdom that uses performance ratings to evaluate organizations, blaming directors when ratings are bad, but with no rewards when good performance is achieved.
\end{abstract}




\section{STEWARDS IN AN “ODD” KINGDOM. PERFORMANCE AND REMUNERATION OF THE BOARDS OF DIRECTORS OF NHS FOUNDATION TRUSTS.}

\section{INTRODUCTION}

The motivation of workers and managers is a key element for the success of any organization. Academic literature in general, and the International Public Management Journal in particular, has devoted significant attention to this issue in the public sector (among others, Anderfuhren-Biget et al. 2010; Choi and Whitford 2017; Langbein 2010; Le Grand 2010; Lewis 2010; Moynihan 2013; Wright and Christensen 2010; Wright, Christensen, and Pandey 2013). Under New Public Management (NPM), performance measures and rewards have become commonplace in public sector organizations. Frey, Homberg, and Osterloch (2013) argue that these measures can raise public servants' motivation and enhance service quality. More pay for better performance (performance-related pay, performance pay, or pay for performance) has long been the mantra behind the personnel reforms under NPM (Bellé 2015). The implementation of PRP initiatives has raised the question of whether public sector professionals, in the words of Le Grand (2010), “are 'knaves', motivated primarily by self-interest, or 'knights', motivated by altruism and the desire to provide a public service."

The adoption of business-like incentive structures in the public sector, in particular, the introduction of performance-related pay (PRP), has been one of the most significant challenges of NPM reforms (Weibel, Rost, and Osterloh 2010). Bellé (2015) states that the use of monetary incentives in the public sector seems to have enjoyed a recent resurgence in interest and popularity. Recently, Bajorek and Bevan (2015) 
conducted a review of the literature on the effectiveness and value for money of PRP in the UK public sector. Their findings were mixed, with PRP scheme effectiveness often dependent on scheme design and organizational context. Several authors argue that PRP may not produce the desired results in the public sector (see, e.g., Christensen, Paarlberg, and Perry 2017; Bellé 2015; Bregn 2013; Brewer and Walker 2013; Langbein 2010; Ritz, Brewer, and Neumann 2016; Weibel et al. 2010). Motivation and pay are more likely to be substitutes than complements in the public sector; therefore, PRP may have unintended adverse consequences and more analyses of the relationship between performance and pay are necessary in this sector (Langbein 2010).

National Health Service (NHS) Foundation Trusts (FTs) are autonomous public sector organizations within the NHS and provide over half of all NHS hospital, mental health, and ambulance services in England. Monitor, an independent public agency, regulates the FTs and monitors their performance using a defined and specific set of performance measures. FTs provide a suitable environment in which to study the implementation of PRP, for three reasons. First, Monitor backs the implementation of some type of PRP mechanism. Second, the top management teams of the FTs are structured in boards of directors. Third, their performance is assessed with specific performance measures which are periodically disclosed and, thus, easy to track.

This paper has two objectives. First, to study the level of implementation of PRP mechanisms to remunerate the boards of directors of the FTs. For this purpose, we review the remuneration sections of the annual reports published by the FTs. Second, to study whether the remuneration of the directors, in particular the executive directors, is linked to the performance of these organizations. For this purpose, we use the structural equation model, partial least square (SEM-PLS) approach, to analyze, in a single model, the relationship between board remuneration and financial performance and service 
quality. The paper provides evidence about the reluctance to and difficulties in adopting PRP in public sector entities, even in a favorable organizational context. The paper is structured as follows. The next section reviews the literature about the impact of PRP mechanisms in the public sector, in general, and in the healthcare sector, in particular. Then, the characteristics of FTs are explained. After the research design and the results sections, findings are discussed and conclusions are drawn.

\section{PERFORMANCE-RELATED PAY IN THE PUBLIC SECTOR}

\section{General Issues about PRP in the Public Sector}

PRP is built on the premise that rewards can foster appropriate behavior and that money is a potentially powerful incentive to influence the efforts that employees will make on behalf of the organization (Suff, Reilly, and Cox 2007). The payments may be made through the form of permanent supplements or lump-sum bonuses. However, compensation systems can either hinder or enhance organizational performance (Condrey, Facer II, and Llorens 2012). PRP is an appeal to the self-interest of workers to improve performance because if the benefits of making more (or different) efforts exceed the costs associated with doing so, they will change their behavior accordingly (Bregn 2013).

The problems related to the implementation of PRP systems exist both in the private and public sectors, although they are more evident in the latter, and include greater difficulties of measuring performance (Langbein 2010). Public organizations have difficulties in defining ex-post or results-oriented control mechanisms (Carlin and Guthrie 2001). In addition, in many occasions the difficulty is to identify those responsible for performance achievements (Mannion and Davies 2008). In order to be effective and to have the potential to inflict reputational damage, performance 
assessments must be robust to criticism from those being assessed, understood by the public, and widely reported (Bevan 2010). Eijkenaar et al. (2013) argue that PRP is more effective when the performance measures are very specific and easy to track.

A robust measure of performance has to fulfill three criteria in public sector organizations (Brewer and Walker 2013). First, it should be a multidimensional measure that covers the many concerns of management, such as quality, efficiency, effectiveness, responsiveness, and equity. Second, there should be general agreement among the stakeholders about what constitutes high levels of performance. Third, performance measures should include a range of information about the organization, some of which may be archival. This could include data from performance indicators, strategic and operational plans, and inspectors' reports.

In addition to performance measurement itself, another problem is that, even though professionals perform individual jobs well, the organization may falter if it does not have the proper mechanisms to connect good individual performance to organizational goals (Lewis 2010). In practice, the attribution of rewards to those responsible for improved performance is difficult (Mannion and Davies 2008). The results of Ducharme, Singh, and Podolsky (2005), in a private sector context, show that performance appraisal and the fact that those evaluated have clear information about the results are fundamental for the success of PRP systems. PRP can be more effective when directed at individuals or small teams than when directed at large groups (Eijkenaar et al. 2013).

PRP is oriented to obtain the desired outcomes and reinforce the behaviors (Perry, Engbers, and Jun 2009). Goal setting theory argues that future goals or anticipated outcomes can be used to influence behavior and motivation and that the mere existence of goals can lead people to behave in ways that help to attain those goals 
(Suff et al. 2007). This theory places less emphasis on rewards and stresses the motivating power of defining appropriate work goals and engaging employee commitment to them (Marsden 2004). Goal setting theory was refined in a number of ways through the expectancy theory, whose main argument is that motivation depends on whether the outcomes hold psychological value or "valence" for the individual (Suff et al. 2007). Therefore, employee effort is determined by valence, i.e., the value of the expected outcome (pecuniary as well as non-pecuniary) associated with a given choice of effort (Bregn 2013).

Many studies have focused on pay as a particularly important motivator in both the public and private sectors, but empirical studies suggest that public employees have a different incentive structure from their private sector counterparts (Kim 2010). The public sector has characteristics which may hinder the adoption of PRP, and theories based on self-interest cannot provide sufficient grounds to analyze the motivation of employees in the public sector (Perry et al. 2009; Weibel et al. 2010). When workers obtain utility from the actions they take in their jobs, they may make the same effort with no additional bonus payments (Dixit 2002). This effect is more likely to occur in the public sector than in the private sector, and government entities may take advantage of this fact, especially when there are budget or financial constraints.

\section{Public Service Motivation and Stewardship Approaches}

The different behavior of private and public sector workers can be explained by the type of rewards and motivations they value most (Wright and Christensen 2010). In the public sector, the public service motivation (PSM) approach has been widely used to explain the behavior of its workers (Carpenter, Doverspike, and Miguel 2012). Bozeman and $\mathrm{Su}$ (2015) provide a review of the concepts involved in the PSM theory and highlight the diversity of the multiple conceptualizations of PSM. In their review, 
they present the evolution of the definitions of PSM, which range from the "individual's predisposition to respond to motives grounded primarily or uniquely in public institutions and organizations" (Perry and Wise 1990) to a broader concept, proposed by Kjeldsen (2012), which includes “individuals' motivation to contribute to society and help other people through the delivery of public services (i.e., services ordered and fully/partly paid for by the public) regardless of whether this takes place in the public or private sectors." French and Emerson (2014) distinguish between public service and public sector motivation, the latter including the intrinsic and extrinsic rewards associated with employment in the public sector such as job security and tenure, career prospects and pension systems.

PSM is not a public sector phenomenon but belongs to all sectors (Bozeman and Su 2015). However, normative commitment -the sense of obligation, duty, and loyaltyis more relevant in the public than in the private sector, due to the nature and content of both the explicit employment contract and implicit psychological contracts (Markovits et al. 2010). Public sector workers share an idealistic and ethical purpose with the entity they work for, so they obtain utility from working in this sector (Dixit 2002). Their commitment is more related to intrinsic rewards (such as self-determination, personal enthusiasm, altruism, reputation, job satisfaction) than to extrinsic rewards (such as salaries or monetary reward) (Anderfuhren-Biget et al. 2010; Georgellis, Iossa, and Tabvuma 2011; Lee and Wilkins 2011). When employees are intrinsically motivated by public service, PRP might harm an initial motivation to perform well in a job (Bregn 2013). Public managers are intrinsically motivated; thus, a pay incentive will not necessarily stimulate them to perform better (Jobome 2006). According to some authors (e.g., Ritz et al. 2016), in the public sector, PRP can be counterproductive. The introduction of PRP reduces the intrinsically motivated component of additional effort 
to a greater extent than it increases the extrinsic component of such effort (Weibel et al. 2010). PRP may often hinder employees from focusing on results that are important to the organization (Langbein 2010). Monetary incentives for activities with a prosocial impact may crowd out employee motivation (Bellé 2015).

Together with PSM, Stewardship theory can also be used to explain top managers' actions in the public sector (see, e.g., Ellwood and García-Lacalle 2015). This theory is seen as a particular case of agency theory in which the owner (principal) and the management (agents) have similar objectives, thus, minimizing traditional principal-agent conflicts (Caers et al. 2006). The Stewardship theory proposes that stewards are motivated to act in the best interests of their principals and make decisions that are in the best interests of the overall organization in cases where different stakeholders express competing objectives (Davis, Schoorman, and Donaldson 1997) because they are motivated by intrinsic, rather than extrinsic, rewards (Boyd, Haynes, and Zona 2011).

\section{Performance and Remuneration in the Healthcare Sector}

The academic literature provides systematic reviews of the specific effect of PRP in the healthcare sector (Eijkenaar et al. 2013; Ogundeji, Bland, and Sheldon 2016; van Herck et al. 2010). Van Herck et al. (2010) found that the effectiveness of PRP programs is highly variable, from negative (rarely) or absent to positive or very positive. Eijkenaar et al. (2013) concluded that there is insufficient evidence to support or not to support the use of PRP in the sector, as the results of the few studies are mixed. Ryan, Blustein, and Casalino (2012) analyzed a PRP program in U.S. hospitals whose main goal was to encourage greater quality improvement, particularly among lowerperforming hospitals. Their findings raise questions about the effectiveness of economic incentives to improve quality in the healthcare sector. Gillam, Siriwardena, and Steel 
(2012), in the UK primary care setting, concluded that observed improvements in quality of care for chronic diseases in the PRP framework were modest and that the impact on costs, professional behavior and patient experience was uncertain. Fleetcroft et al. (2012) found similar results, with no association between the size of the financial incentive and outcomes. Ogundeji et al. (2016), after a meta-analysis of PRP mechanisms in healthcare, conclude that their effectiveness in improving healthcare performance has been variable and modest, particularly in improving health outcomes. Moreover, they state that evaluations are often poorly designed and lack adequate controls and, so, over-estimate the results of these mechanisms.

Our study is focused on the remuneration of the boards of directors of public hospitals. Academic literature on this topic is scarce, focused on the remuneration of the CEOs, and mainly carried out in the U.S. context where CEO compensation in government hospitals is significantly lower than in private non-profit hospitals (Ballou and Weisbrod 2003; Eldenburg and Krishnan 2003). Ballou and Weisbrod (2003) found that the CEOs of government hospitals receive lower bonuses than those of private nonprofit hospitals. This lower remuneration might be due to poor selection, government hospitals do not hire the best executives, or incentive problems (Ballou and Weisbrod 2003; Eldenburg and Krishnan 2003). However, Ballou and Weisbrod (2003) also provide another interpretation: an unmeasured compensating differential. CEOs who prefer to work in the public sector may be willing to accept lower cash compensation in exchange for the opportunity to work in this particular environment, characterized by, for example, greater job security and low stress levels. Weibel et al. (2010) argue that PRP can successfully boost personal efforts in the case of less interesting tasks, but managers perform tasks that are intrinsically motivating, which reduces the validity of PRP in this group of qualified workers. Hospitals that have incentive programs are 
much more likely to reward the strong financial performance of CEOs than the production of high quality care (Ballou and Weisbrod 2003; Preyra and Pink 2001).

Newton (2015) found, in large non-profit U.S. hospitals, a negative and statistically significant relationship between CEO compensation, measured as the CEOto-employee relative pay, and organizational performance which may be due to poor governance quality. Cardinaels (2009), for Dutch non-profit private hospitals, found that CEOs, on average, earn more when the hospital's supervisory board members have a lower level of expertise and receive more remuneration.

Ballantine, Forker, and Greenwood (2008) study the relationship between CEO pay, CEO turnover and organizational performance in NHS acute hospital trusts. NHS trusts were the predecessors of the NHS FTs. These authors found a significant relationship between low performance, in particular for financial performance, and CEO turnover, but they did not find any relationship between financial performance and CEO pay or between service quality and CEO pay. Ballantine et al. (2008) excluded FTs from their analyses because they warrant separate study and called for further research to investigate these relationships in FTs.

\section{GOVERNANCE, REMUNERATION AND PERFORMANCE ASSESSMENT IN THE FTs}

FTs are autonomous public sector organizations within the NHS. FTs provide over half of all NHS hospital, mental health, and ambulance services in England. They are managed by a board of directors and operate in a context of competition, because patients can choose the hospital in which they are treated. The FTs authorized at the end of the $2012 / 13$ financial year generated total revenues of almost $£ 39$ billion with nearly 600,000 professionals working on whole time equivalents (Monitor 2013a). 
The FTs operate in a strong governance environment (see e.g., Ellwood and Garcia-Lacalle 2016). The FTs governance structure consists of two boards: a board of governors and a board of directors. The board of governors represents the interests of FT members and partner organizations in the local community, holds the board of directors to account for the performance of the FT, and exercises statutory duties. This board acts like a parliament. The board of directors consists of both executive and nonexecutive directors and has great freedom to decide its own strategy and the way services are run. Its members "are ultimately and collectively responsible as a board for all aspects of the performance of the foundation trust" (Monitor 2010, 4). Therefore, the board of directors is a clearly identifiable "small" team responsible for the performance of the FT. The executive directors manage the day-to-day operational and financial performance of the FT. The non-executive directors do not have responsibility for the day-to-day management, but share the board's collective responsibility for ensuring that the organization is run efficiently, economically, and effectively. They scrutinize the executive management's performance in meeting agreed goals and monitor the reporting of performance.

Monitor, an independent regulatory body, authorizes NHS organizations to become FTs and is responsible for ensuring that FTs are well governed in terms of service quality and financial performance. Monitor has issued a Code of Governance (The Code), with a "comply or explain" approach, to help FT boards to improve their governance practices.

Non-executive directors "are responsible for determining appropriate levels of remuneration of executive directors" (Monitor 2010, 10). The Code's provisions include the establishment of a remuneration committee composed of non-executive directors. This committee is responsible for setting the remuneration of the executive directors 
and decides whether a proportion of the executive directors' remuneration should be linked to corporate and/or individual performance, including annual bonuses. The main principle for establishing the remuneration of the directors of the FTs is set in Monitor's Code of Governance: "Levels of remuneration should be sufficient to attract, retain and motivate directors of the quality and with the skills and experience required to lead the NHS foundation trust successfully, but an NHS foundation trust should avoid paying more than is necessary for this purpose" (Monitor 2010, 23). This principle is clarified with supporting principles to help remuneration committees to set pay levels. The remuneration committees should consider whether the executive directors are eligible for annual bonuses. If so, "performance conditions should be relevant, stretching and designed to match the long term interests of the public and patients" (Monitor 2010, 23). For the chairman and other non-executive directors, the Code recommends that their levels of remuneration should reflect the time commitment and responsibilities of their roles. External professional advice is usually used to set the remuneration of the non-executive directors according to the benchmarks for this activity.

FTs must disclose detailed information about the remuneration of executive and non-executive members of the board. Performance criteria and any upper limits for annual bonuses and incentive schemes should be set and disclosed (Monitor 2010). In addition, FTs were required by Monitor (2013b) to disclose, in the remuneration section of their annual reports, for each senior manager, the salary and allowances, performance-related bonuses, contribution to pension plans and other relevant information, in bands of $£ 5,000$. This information was subject to audit. In addition, narrative, non-audited information, such as the policy on the remuneration of senior managers for current and future financial years, must be reported. In particular, "an explanation of relative importance of the relevant proportions of remuneration which 
are, and which are not, subject to performance conditions" (Monitor 2013b, 80).

Following the Hutton report of fair pay (Lord Hutton Report 2011), remuneration should be considered, and reported, both in absolute terms and in terms of the level of remuneration of the workforce. This information is known as the "Hutton disclosure." Therefore, FTs informed about the remuneration of the highest paid director, as well as the relationship between this remuneration and the median remuneration of the organization's workforce.

FTs have the freedom to set the remuneration of their managers and workers, but they remain part of the NHS and, thus, influenced by the situation of the public sector in general, and the Department of Health $(\mathrm{DoH})$ and the NHS in particular. The financial year analyzed (2012/13) was within the period of financial constraints in the public sector due to the last financial crisis. In 2010, at the beginning of this crisis, the DoH issued a document that established some principles to manage the NHS, the largest public service in the country, which included a statement about the need for fiscal consolidation and required sustained pay restraint across the NHS (DoH 2010).

Monitor measures the performance of the FTs. For the financial year 2012/13, Monitor's assessment was conducted under the Compliance Framework (Monitor 2012). This framework used a rating approach that provided an indication of whether the FT was well governed, financially robust and met the required quality threshold. Monitor's regulatory process consisted of several stages, including monitoring, risk assessment, and intervention, if necessary. When a FT consistently failed to meet national standards of care or was at financial risk, Monitor increased its surveillance, required it to explain why it had failed and to develop a plan for fixing the problem. If the problems continued, Monitor could use its statutory powers of intervention. These powers included, among others, the possibility of requiring the board to seek external 
advice and even to remove all the members of the board of directors and appoint interim directors (Monitor 2012).

Monitor assessed financial performance using the financial risk rating (FRR), which has a 5-level scale (" 1 " worst performance and " 5 " best performance). The FRR assessment included the analysis of financial performance, financial efficiency and liquidity. Service quality is mainly measured using the governance risk rating (GRR), which is a 4-traffic-light system: green (best performance), amber-green, amber-red and red (worst performance). The GRR assessment included the monitoring of service performance scores in areas such as compliance with quality indicators of patient safety, clinical effectiveness and patient experience, and compliance with the delivery of mandatory services. Therefore, FTs had clear and specific overall performance ratings which allowed Monitor to establish their level of financial performance and service quality. FTs ratings were published in the website of Monitor and in their websites and their annual reports, so stakeholders had a clear idea of the performance of the FTs. These ratings were key for FTs because they were the ones used by Monitor to assess their financial performance and service quality. Depending on the ratings achieved, Monitor modulated its surveillance intensity and decided whether to intervene or not in the management of the FTs.

The existence of a transparent performance regime and the presence of boards of directors that are responsible for the performance of these organizations create a favorable organizational context for adopting PRP mechanisms in the FTs. Our analyses aim to determine whether the implementation of PRP mechanisms in FTs has taken place and to identify factors that explain the remuneration of their directors, paying particular attention to the relationship between performance and remuneration. 


\section{RESEARCH DESIGN}

\section{Sample and Methodology}

In the financial year 2012/13, there were 144 FTs suitable for the analysis (with data for the whole financial year). The four ambulance FTs have been excluded because they provide a different service from the other FTs. Both qualitative and quantitative analyses have been carried out. First, a qualitative content analysis of the remuneration section included in the annual reports for the year 2012/13. In this qualitative analysis of the 140 FTs, we looked for the following information required by Monitor in its reporting manual for 2012/13 (Monitor 2013b): 1) explanation of the remuneration policy, that is, some statement about the main mechanisms used for setting the remuneration of the executive members of the boards; 2) explicit statements about the adoption, or not, of a PRP scheme in the FT; 3) whether the tables with the salary and pension entitlements of senior managers included a column with the bonus received by the members of the boards; and 4) the bonuses reported. This last item, the disclosure of performance-related bonuses, was reported in bands of $£ 5,000$ and subject to audit.

Quantitative analyses allow us to study whether remuneration compensates for higher levels of performance and whether there are undisclosed PRP mechanisms when organizations do not report paying bonuses. Our quantitative analysis has been carried out with data referring to two financial years (2012/13 and 2011/12), that have been obtained directly from FTs' annual reports and financial statements, available from either Monitor's or the FTs' websites. For the analysis using only data for 2012/13, our sample consists of $130 \mathrm{FTs}$, more than $90 \%$ of the total FT population for the year. For the analysis that includes data for 2011/12, our sample consists of 122 FTs. Some FTs were not taken into account for the quantitative analyses because of missing data. The 
Mid Staffordshire FT has also been excluded because, during that year, it was subjected to intervention by Monitor.

The structural equation model, partial least square (SEM-PLS) approach, with SmartPLS 2.0 software, has been used for the quantitative analysis. The main advantages of this technique are the following: 1) It can use constructs as variables. Constructs are made up of several items or indicators to better capture the characteristics of the complex "reality" to be studied, strengthening the results and their interpretation. 2) It allows the inclusion of more than one dependent variable in the same model. 3) It allows the study of interactions among variables (or constructs), so complex relationships between variables with direct and indirect effects can be tested (Serrano-Cinca, Fuertes-Callén, and Gutiérrez-Nieto 2007). 4) Lastly, while other approaches to the SEM (such as covariance-based methods) have strong sample-size requirements, PLS restrictions are generally much smaller.

\section{Measurement of Variables for the Quantitative Analysis}

\section{Dependent Variables: Expenses per Board Member}

Two constructs have been created to capture the remuneration of board members: ExecDirRemun and NonExecDirRemun. ExecDirRemun is a construct made up of two items. The first is the natural log of the average total expenses per executive director (meanExecExp), calculated as total expenses of the executive directors in the FT divided by the number of executive directors. We include a second item (relatExecExp) that compares the remuneration of the executive directors to the salary level of the rest of the staff. This item is measured as the ratio of the average expenses per executive director divided by the average expenses per employee. The inclusion of the "relative salary" item is in line with the analysis carried out by Newton (2015) and with the idea underlying the "Hutton disclosure." The inclusion of these two items in 
the same construct allows us to better capture the average level of the remuneration of the executive directors (both in total and relative terms). NonExecDirRemun is a construct made up of two items, in a similar way to ExecDirRemun: meanNonexecExp is the natural $\log$ of the average total expenses per non-executive director, calculated as total expenses of non-executive directors divided by the number of the non-executive directors, chairperson included; and relatNonexecExp, which is the ratio of the average expenses per non-executive director divided by the average expenses per employee. The number of board members, both executive and non-executive, has been considered as those at the end of the financial year, as disclosed in the annual report. We use the total expenses incurred by FTs in relation to executive and non-executive directors as a proxy for their overall remuneration for two reasons. First, individual information for the salary and other remuneration was provided in salary bands of $£ 5,000$. Second, total expenses include all possible benefits received by board members, short term, postemployment, and termination benefits (Monitor 2013b).

\section{Explanatory Variables: Performance Ratings}

Two constructs have been created with the quarterly ratings, one for financial performance $(F P)$ and one for service quality $(S Q)$, obtaining two measures that reflect the multidimensional performance of the FTs. The option of using constructs to capture annual performance is more adequate than using only the ratings of the fourth quarter or than calculating the average rating for the year. An average rating would mean treating a FT which has obtained ratings of 4, 4, 2 and 2 and a FT which has consistently achieved a rating of 3 throughout the year as equals. Monitor would have enforced different actions in each case. FP includes the FRRs for the 4 quarters (from " 5 " best performance to " 1 " lowest performance). $S Q$, the measurement of service quality, 
transforms the colors of the GRRs into numbers: green = "4"; amber-green = " 3 "; amber-red = "2"; and red $=$ "1."

\section{Control Variables: Organizational Characteristics}

The following variables have been introduced into the model to control for organizational characteristics that may influence the remuneration of the boards of directors: size, the type of services provided (mental or acute), location and the complexity of the assets managed. Size is included as a construct made up of three indicators (in their natural log form): book value of total assets at the end of the year, total operating income during the year and full-time equivalent staff during the year. The rest of the control variables are included as single indicators. The use of single-item indicators (or constructs) is not restricted in PLS (Hair et al. 2012). In order to capture the type of services provided by each FT, the classification of the Hospitals Estates and Facilities has been used. This classification distinguishes 3 main categories of FTs: mental and care hospitals, acute hospitals and ambulance services. As stated, ambulance FTs have been excluded from the analyses. Therefore, a dummy variable, type of services, has been defined: " 1 " when the FT is a mental health hospital and " 0 " for acute hospitals. Location is represented by a dummy variable which takes value "1" for FTs located in the London or the South East Coast areas and "0" otherwise. According to the DoH (2012), these areas have the highest costs. The complexity variable is the proportion of the book value of non-current assets over the book value of total assets and it is used as a measure of an entity's strategic flexibility (Newton 2015).

\section{Model Specification}

Figure 1 shows the model tested with SEM-PLS. The constructs for the remuneration of the executive and non-executive directors are the dependent variables in our model. FP and SQ capture the performance of the FTs, according to their 
financial and service quality ratings, respectively. Size, type of services, location and complexity are included in the model as control variables to study their direct relationship with the remuneration of both executive and non-executive directors as well as their indirect association with these remunerations through their relationship with performance. Because the relationship between performance and pay might be somewhat delayed, that is, short-term payments for performance may be effective in the same or the following year, we build two SEM-PLS models. Directors' remuneration refers to the year 2012/13 in the two models. In Model 1, with 130 FTs, the performance, FP and SQ, and control variables correspond to the 2012/13 financial year. In Model 2, with 122 FTs, the performance and control variables correspond to $2011 / 12$

$<<<$ Insert Figure 1 about here $>>>$

In Figure 1, ellipses represent constructs made up of several items. Rectangles represent single-item constructs. If PRP mechanisms were based on Monitor's ratings, $F P$ and/or $S Q$ would show a positive association with the remuneration of executive directors. Another relationship tested in the model is the relationship between the remuneration of non-executive directors and executive directors. As indicated above, non-executive directors set the remuneration of executive directors. Cardinaels (2009) indicates that CEOs earn more when the hospital's supervisory board members receive more remuneration. Therefore, a positive relationship between the remuneration of the non-executive directors and the executive directors is expected. The model also includes the relationship between the performance measures and the remuneration of nonexecutive directors. No significant relationship is expected because external professional advice is usually used to set the remuneration of the non-executive directors according to the benchmarks for this activity. 


\section{RESULTS}

\section{Descriptive Statistics}

The main descriptive statistics of the variables included in the analyses are presented in Table 1. The figures in Table 1 show the importance of the 130 FTs included in our analyses. These FTs had an income of $£ 35$ billion in 2012/13 and more than half a million workers. In the two financial years analyzed, the FTs had a good financial performance, with average quarterly FRRs of more than 3 and good GRRs, an average of 3, equivalent to an amber-green rating. However, the minimum values and the relatively high standard deviations of the FRRs and GRRs indicate that some FTs operated in a risky financial and service quality context. The total expenses related to the boards of directors were $£ 145.5$ million, $£ 128$ million for the executive directors and the rest for the non-executive directors. On average, the average expenses per executive director was 3.84 times the average expenses per worker whereas, for non-executive directors, this ratio was 0.5 .

$<<<$ Insert Table 1 about here $>>>$

\section{Results of the Qualitative Analyses: Review of the Remuneration Reports}

We have reviewed explanations about 1) the remuneration policy, 2) statements about the adoption, or not, of a PRP scheme, 3) the presence of a column for bonuses and 4) the bonuses reported. Table 2 shows the results of our review.

$$
<<<\text { Insert Table } 2 \text { about here }>>>
$$

Table 2 shows that $27 \%$ of the FTs disclosed no information about how the remuneration of their executive directors was set. $14 \%$ reported conducting a benchmark process. $41 \%$ of the FTs indicated that the remuneration of the executive directors was set with a combination of a benchmark and performance appraisals. $17 \%$ 
informed about conducting performance appraisals when setting the remuneration of their executive directors. Therefore, almost $60 \%$ of the FTs reported some performance appraisal in relation to the remuneration of their executive directors. In terms of whether the FTs had a PRP scheme to remunerate their executive directors, 66 FTs (47\%) did not inform about this issue. Of the 74 FTs (53\%) that informed about this aspect, only 18 FTs explicitly declared having a PRP, whereas 56 FTs declared not having one.

In the 2012/13 annual reports, the FTs that indicated that they conducted performance appraisals did not disclose information about how the appraisal was carried out, e.g., the indicators used or targets set, except for one FT (South West Yorkshire Partnership) that reported the specific corporate goals to be achieved. This was the only FT that clearly stated that there was a bonus (1.5\%) linked to the achievement of corporate targets based on Monitor's ratings. Additional individual bonuses were also possible, subject to the achievement of corporate objectives. This FT did not award any bonus in 2012/13 because the corporate objectives for 2011/12 were not achieved.

An example that illustrates the reluctance to pay bonuses to the executive directors is the statement made in the annual report of North East London FT (NEL 2013, 22): "Performance is assessed in relation to both organisational performance against agreed objectives and external measurements including regulatory information, and individual performance against annual personal objectives and contribution to the performance of the organisation. It is the current policy of the [remuneration] committee not to award any performance related bonus or other performance payment to executive directors." On occasions, performance was assessed not for remuneration purposes, but for the continuation of the executive directors in office, as stated, for example, in the annual report of the Chesterfield Royal Hospital (CRH 2013, 107): "The Trust does not operate performance related-pay or bonuses. The performance of the Executive 
Directors is assessed on a continuing basis via formal appraisal and unsatisfactory performance may provide grounds for termination of contract."

One example that shows the difficulties of paying bonuses can be found in the North Tees and Hartlepool Hospitals. This FT has had a PRP scheme in force since 2008, when the remuneration committee approved one that measured both individual and collective performance, which would not be greater than $10 \%$ of directors' salaries. The remuneration section stated (NTH 2013, 173): “All key indicators were achieved [for the financial year 2011/12] which would have indicated a bonus payment [in 2012/13]. However, taking account of the current financial climate and the outcomes of national NHS pay negotiations, the Remuneration Committee decided to recognise the commitment and performance of the Executive team over the last year but not provide for a bonus payment."

In the search for a column with bonuses, 26 FTs (18.7\%) had one. Only 9 FTs reported paying any bonus. The total bonuses paid amounted to $£ 354,000$, less than $0.3 \%$ of the total expenses of the executive directors, including $£ 174,000$ (4 FTs) received by their medical directors within the national Clinical Excellence Award Program. Part of the bonuses reported corresponded to results achieved in the previous year.

The qualitative analysis about the remuneration policies and bonuses disclosed in the annual reports indicates that PRP mechanisms were not popular among FTs to remunerate executive directors. In addition to this qualitative analysis, the quantitative analysis allow us to explain in greater depth factors related to the remuneration of directors, paying special attention to the performance attained and, thus, to the existence of undisclosed performance-related remuneration. In particular, we study whether 
Monitor's ratings were used to reward directors, particularly executive directors, either as salary or some other type of remuneration different from bonuses.

\section{Results of the Quantitative Analyses: The Structural Equation Model}

PLS analysis must be carried out in two independent stages: the measurement model analysis and the structural model analysis. The measurement model assessment involves the examination of the adequacy of the measurement scales. The analysis of the structural model focuses on testing the relationships between the constructs that compose the theoretical model.

\section{Results of the Measurement Model}

The results of the measurement model presented in this section are those of Model 1 (all the data refer to the financial year 2012/13). The results of Model 2, oneyear lag, show only minimal variations in the figures corresponding to these constructs and fulfill all the criteria to validate the measurement model. Therefore, results are not presented.

We estimate the measurement model with PLS in order to analyze internal consistency. This process essentially involves three stages (Roldán and Sánchez-Franco 2012). First, the unidimensionality of the indicators is evaluated using their factor loadings $(\lambda)$. This permits an evaluation of whether or not each indicator of the construct is highly correlated with the characteristic that it intends to capture. All the factor loadings $(\lambda)$ in Table 3 exceed the threshold of 0.7 . Second, reliability is explored using Cronbach's Alpha for simple reliability and the CRI value to measure composite reliability. Reliability indicates whether or not the set of variables are consistent in what they intend to measure. All the Cronbach's Alpha coefficients and CRI values exceed the critical threshold of 0.7 (Carmines and Zeller 1979; Nunnally 1978). Third, validity 
is assessed by using convergent validity and discriminant validity. Convergent validity is analyzed through average variance extracted (AVE) values and evaluates the degree to which the indicators represent the construct. Table 3 shows that all the AVE values are above 0.5 , which guarantees convergent validity (Fornell and Larcker 1981). Discriminant validity indicates whether each construct in the model is significantly different from the others. The most accepted method to check for discriminant validity in PLS is the comparison of the square root of the AVE values and the correlation among variables (Chin 1998). Table 4 presents the square root of each construct's AVE values on the diagonal, and the estimated correlations for each pair of constructs off the diagonal. This table confirms, for the 2012/13 financial year, the existence of discriminant validity between the constructs since the square root of each AVE value is higher than the estimated correlations.

$<<<$ Insert Table 3 about here $>>>$

$<<<$ Insert Table 4 about here $>>>$

\section{Results of the Structural Model}

Having confirmed the adequacy of the measurement scales for the constructs included in the model, the structural model is estimated. The results of two models are presented in Table 5. In Model 1, all the data refer to 2012/13. In Model 2, the data for the control variables and $F P$ and $S Q$ refer to 2011/12.

$<<<$ Insert Table 5 about here $>>>$

To assess the significance of the path coefficients $(\beta)$, a bootstrapping procedure with 5,000 subsamples has been used. Smart-PLS does not provide a global indicator of the goodness of fit of the whole model. To evaluate the predictive relevance of the model, the Stone-Geisser test is used. The $\mathrm{Q}^{2}$ value of this test for the remuneration variables is positive in the two models, thereby supporting the predictive relevance of 
the model. The structural model is examined by observing the $\mathrm{R}^{2}$ values of the remuneration variables. Model 1 explains $24 \%$ of the variance in the construct reflecting the remuneration of executive directors and $11 \%$ of the variance in the construct reflecting the remuneration of non-executive directors. These figures are $23 \%$ and $19 \%$ in Model 2. The two models show a similar $\mathrm{R}^{2}$ for the remuneration of executive directors, the main focus of our study, whereas Model 2, one-year lag, better explains the remuneration of non-executive directors. Nonetheless, the results of the two models show that neither financial performance nor service quality is related to the remuneration of the executive directors. The size of the FTs is the only factor, for the two years, that is associated, at the 0.01 level, with this remuneration. Bigger organizations pay more to their executive directors. The remuneration levels of nonexecutive directors, which form the remuneration committees, are not significantly related to the remuneration levels of executive directors. That is, it seems that nonexecutive members do not use their salary as a reference to set the remuneration of their executive counterparts. Being located in the London or South East Coast areas has a negative association with the remuneration of the non-executive directors. On the contrary, size and being a mental health hospital have a positive association with the remuneration of these directors.

Finally, although the analysis of the variables associated with the financial and quality performance is beyond the scope of this paper, different organizational factors, namely, the type of services provided, location and hospital complexity, are associated with financial performance, service quality or both. According to the results of Model 1, these factors explain about $30 \%$ of the variance of the financial performance $(F P)$ and more than $25 \%$ of the service quality (SQ) of the FTs for the 2012/13 financial year. In particular, being a mental hospital and being located in the London or South East Coast 
areas are related to obtaining better performance ratings, whereas more complex hospitals have greater difficulty in achieving good ratings.

\section{DISCUSSION}

NHS FTs enjoy great freedom and flexibility in setting the remuneration of their top managers, operate in a transparent performance regime and are managed by a board of directors. These circumstances provide a favorable environment for implementing PRP mechanisms. However, a favorable organizational context does not seem to be enough. The results of our qualitative analyses indicate that these entities had not adopted these mechanisms in the year analyzed or, if they had, they resulted in hardly any bonus payments.

The most common remuneration policy for executive directors reported by FTs was a combination of benchmark and performance appraisals. The benchmark was mainly based on some "market rate" using local comparisons or salary surveys for NHS executive directors. It is not possible to know how performance appraisals were carried out, or what indicators were used for the appraisal, because no specific indicators were disclosed in the annual reports. Thus, the transparency required for performance assessments to be effective is not achieved and further research (e.g., surveys/interviews) is needed to clarify the specific measures used in the performance appraisals. There seems to be a formal adherence to the adoption of the remuneration policy envisaged by Monitor, which sets several recommendations about how to link performance and remuneration, as $60 \%$ of the FTs state that they use some form of performance appraisal.

The number of FTs that clearly state having a PRP scheme is very low, less than $15 \%$, with just one FT disclosing the use of Monitor's ratings scores to set the targets on 
which bonuses are based. The proportion of FTs that reported paying any bonus is even lower. Excerpts from the remuneration sections show the reluctance of FTs to pay bonuses, with performance being assessed not for remuneration purposes, but for the continuation of the executive directors in office. The case of the North Tees and Hartlepool Hospitals also shows that sometimes the public sector faces additional difficulties when adopting PRP, as paying bonuses may not be considered appropriate in a general context of budget and financial constraints. In this case, although the executive directors had achieved the targets and, thus, had the right to receive a bonus, the remuneration committee rewarded them with recognition rather than money.

In addition to the qualitative analysis, a quantitative analysis, using structural equation models, has been conducted to determine what factors are associated with the remuneration of the members of the boards of directors, particularly executive directors, and whether there is a relationship between Monitor's performance ratings and remuneration. These performance ratings were key for FTs because they were the ones used by Monitor to assess their financial performance and service quality. The size of the FT has been found to have a positive and significant association with the remuneration of executive directors, which seems logical because bigger hospitals manage more resources and have higher activity levels, resulting in more work for them.

Contrary to the study of Cardinaels (2009), we have found no significant association between the remuneration of non-executive directors, the only directors that can belong to the remuneration committee, and the remuneration of executive directors. Hospital location, hospital size and the type of services provided are associated with the remuneration of the non-executive directors. These results indicate that benchmarking 
processes, based on organizational characteristics, are conducted when setting the remuneration of these directors.

Our results show that there is no relationship between Monitor's performance ratings and the remuneration level of the executive directors. This finding is in agreement with the Cockburn Report about Pay for NHS Very Senior Managers (Cockburn 2012) which states that, although FTs are public sector bodies that have the freedom to set salaries, they do not tend to use this flexibility. For public sector professionals, within the PSM framework, intrinsic rewards may be more important than extrinsic monetary rewards. Moreover, accepting bonus payments might be perceived as an incentive that would focus them on achieving individual benefits rather than on the performance of their organizations.

PSM and Stewardship theories help us to justify the lack of adoption of PRP mechanisms in FTs. According to these theories, stewards' interests and motivations are directed to organizational, rather than personal, objectives. Individuals working in the public sector are usually motivated by altruism, not by self-interest; their strong organizational commitment helps them to align their behavior with the overall objectives of the organization (Markovits et al. 2010). In addition, public sector workers value other intrinsic rewards such as job satisfaction or reputation. For public sector organizations, strong reputation is a competitive advantage and a valuable political asset because it can be used to generate public support to obtain higher levels of autonomy, to protect the entity from political attack, and to recruit and retain valued employees (Wæraas and Byrkjeflot 2012). Reputation might be especially important for FTs' executive directors because of the prominent role they play in these key public sector organizations. Receiving bonuses for "doing their job" might damage the opinion of citizens and patients about those who manage such key organizations for them, that is, 
"their public hospital". According to Ellwood and Garcia-Lacalle (2015), the stewardship approach of FT boards enhances their focus on the interests of their key stakeholders. Therefore, there seems to be no need to pay more for better performance scores.

The results of the quantitative analysis are consistent with the results of the qualitative analysis. No PRP mechanisms using Monitor's ratings are detected. As stated, this indicates both reluctance to and difficulties in adopting PRP in public sector entities. However, due to the nature of our research, other explanations may be valid, and we cannot completely discard them. One possible explanation for the lack of bonus payments in the FTs might be that their boards of directors did not achieve their targets, in particular because, the years analyzed fall within a period of financial crisis. If the lack of bonus payments is because boards of directors consistently failed to achieve their targets this would be indicative of generalized problems in the design of PRP mechanisms. Second, some FTs might be using other performance measures, at the individual or collective level, to reward their executive directors. However, this is highly unlikely because of the low levels of disclosure of bonus payments in the remuneration reports. In addition, the use of other performance measures may not fulfill some of the effectiveness criteria pointed out by Bevan (2010), such as being widely reported and understood by the public.

According to Monitor, the members of the board of directors are ultimately and collectively responsible for all aspects of the performance of the FTs. However, according to Mannion and Davis (2008), in many occasions, the identification of those responsible for performance achievements and the attribution of rewards is difficult. The lack of adoption of PRP mechanisms to remunerate board members in FTs may also aim to avoid tensions between board members and other managers who may also 
consider themselves to have a great deal of responsibility for performance achievements in this highly professional environment.

Further research is needed to ascertain whether PRP in the public sector is effective, perverse or unnecessary. The adoption of PRP is a pre-requisite for this type of analysis, which is not the case in the context analyzed. Thus, our study does not allow us to provide arguments about whether executive directors are knights or knaves. On the contrary, our results suggest another role for the executive directors of NHS FTs. They act like stewards in an "odd" kingdom that uses performance ratings to evaluate organizations, blaming directors when ratings are bad, but with no rewards when good performance is achieved. In the "NHS kingdom," the relationship between organizational performance and CEO turnover is significant (Ballantine et al. 2008), whereas that between performance and pay is not.

Performance measurement is a key element when implementing a PRP scheme and the results of our quantitative analyses have shown that some organizational factors over which managers have little or no control, influenced Monitor's ratings. Thus, these ratings are capturing, in part, organizational differences, rather than managerial action. In the context analyzed, if Monitor's performance ratings had been used to implement PRP, the directors of some hospitals would have had problems in getting bonuses. Some of the internal organizational characteristics of these hospitals (type, location and complexity) have an influence on organizational performance and are beyond directors' direct capacity for action. Therefore, caution is needed with the performance measurement system when adopting PRP in the public sector.

Before concluding this section, the limitations of this study have to be acknowledged. First, we have studied the performance-remuneration relationship in the short term, with cross-sectional data and a one-year lag for performance figures. Future 
studies could also analyze this relationship in the long term, including years with more favorable economic conditions. Second, as indicated above, some FTs report conducting individual and collective performance appraisals, so they might be using performance measures different from Monitor's ratings, at the individual or collective level, to reward their executive directors. Although, in the year analyzed, hardly any FT reported bonuses, future research should analyze the relationship between performance ratings and the individual remuneration of directors.

\section{CONCLUSIONS}

The adoption of performance-related pay (PRP) continues to be one of the most significant challenges of public sector reforms. The problems of defining and assessing performance in public sector organizations and of identifying those responsible for the achievements make it difficult to translate performance into monetary rewards. This study analyzes the remuneration of the members of the boards of directors of NHS FTs using a qualitative approach, content analysis of the annual reports, and a quantitative approach, a structural equation model. FTs provide a favorable context in which to study the introduction of these mechanisms in public sector organizations: they have the freedom to implement PRP mechanisms and that implementation is backed by their watchdog; they operate within a transparent performance regime and are managed by boards of directors within a strong corporate governance context. However, having a favorable organizational context does not seem to be enough, which shows that the adoption of PRP mechanisms is neither easy nor immediate.

FTs declare some performance appraisal to evaluate their executive directors, which indicates a formal adoption of recommendations envisaged by their regulator, Monitor. However, they are reluctant to adopt and enforce PRP mechanisms and, when 
adopted, they do not provide details about their functioning. Our results show that the remuneration of the executive directors is related to the size of the FT, but neither the financial performance nor service quality ratings are related to the remuneration of executive directors. The remuneration of non-executive directors is mainly set using benchmark processes.

The Public Service Motivation approach and the Stewardship theory help to explain the lack of adoption of PRP: executive directors, aware of the importance of achieving good performance in this key public service, may not need monetary rewards to do their job. In any case, our results indicate both reluctance to and difficulties in adopting PRP in public sector entities. These results suggest that the executive directors of NHS FTs are stewards in an "odd" kingdom, who do not receive bonuses when performance is good, but who can be punished (e.g., with contract termination) for bad performance.

\section{ACKNOWLEDGEMENTS}

This work was supported by the Spanish National R\&D Plan under Grant ECO201566240P (MINECO/FEDER); the Government of Aragón/FEDER under Grant Gespública (S56-17R); and the University of Zaragoza under Grant JIUZ-2017-SOC11. The authors also thank the anonymous reviewers and the editor for their valuable feedback.

\section{REFERENCES}

Anderfuhren-Biget S., F. Varone, D. Giauque and A. Ritz. 2010. "Motivating Employees of the Public Sector: Does Public Service Motivation Matter?" International Public Management Journal 13(3): 213-246.

Bajorek, Z.M. and S.M. Bevan. 2015. "Performance-related-pay in the UK public sector. A review of the recent evidence on effectiveness and value for money." Journal of Organizational Effectiveness: People and Performance 2(2): 94-109.

Ballantine, J., J. Forker and M. Greenwood. 2008. "The Governance of CEO Incentives in English NHS Hospital Trusts.” Financial Accountability \& Management 24(4): 385410. 
Ballou, J.P. and B. A. Weisbrod. 2003. "Managerial rewards and the behavior of forprofit, governmental, and nonprofit organizations: evidence from the hospital industry." Journal of Public Economics 87: 1895-1920.

Bellé, N. 2015. "Performance-Related Pay and the Crowding Out of Motivation in the Public Sector: A Randomized Field Experiment." Public Administration Review 75(2): 230-241.

Bevan, G. 2010. 'Performance Measurement of 'Knights' and 'Knaves': Differences in Approaches and Impacts in British Countries after Devolution." Journal of Comparative Policy Analysis: Research and Practice 12(1-2): 33-56.

Boyd, B.K., K.T. Haynes and F. Zona. 2011. "Dimensions of CEO-Board Relations." Journal of Management Studies 48(8): 1892-1923.

Bozeman, B. and X. Su. 2015. "Public Service Motivation Concepts and Theory: A Critique." Public Administration Review 75(5): 700-710.

Bregn, K. 2013. "Detrimental Effects of Performance-Related Pay in the Public Sector? On the Need for a Broader Theoretical Perspective." Public Organization Review 13(1): 21-35.

Brewer, G.A. and R. M. Walker. 2013. "Personnel Constraints in Public Organizations: The Impact of Reward and Punishment on Organizational Performance." Public Administration Review 73(1): 121-131.

Caers, R., C. Du Bois, M. Jegers, S. De Gieter, C. Schepers and R. Pepermans. 2006. "Principal-Agent Relationships on the Stewardship-Agency Axis." Nonprofit Management \& Leadership 17(1): 25-47.

Cardinaels, E. 2009. "Governance in non-for-profit hospitals: Effects of board members' remuneration and expertise on CEO compensation." Health Policy 93: 64-75.

Carlin, T. and J. Guthrie. 2001. "The new business of government budgeting: Reporting non-financial performance information in Victoria." Australian Accounting Review 11(3): 17.

Carmines E. and R. Zeller. 1979. "Reliability and validity assessment". In Sage University Paper Series on Quantitative Applications in the Social Sciences 07-017 Beverly Hills, CA: Sage.

Carpenter, J., D. Doverspike and R.F. Miguel. 2012. "Public service motivation as a predictor of attraction to the public sector." Journal of Vocational Behavior 80: 509523

Chin, W.W. 1998. "Issues and opinions on structural equation modeling." MIS Quarterly 22(1): 7-16.

Choi, S. and A.B. Whitford. 2017. "Employee Satisfaction in Agencies with MeritBased Pay: Differential Effects for Three Measures." International Public Management Journal 20(3): 442-466.

Cockburn, B. 2012. Report on Locality Pay for NHS Very Senior Managers 2012 (Report No. 80). London, UK: Office of Manpower Economics.

Condrey, S.E., R.L Facer II and J.J. Llorens. 2012. "Getting It Right: How and Why We Should Compare Federal and Private Sector Compensation." Public Administration Review 72(6): 784-785. 
Christensen, R.K., L. Paarlberg and J.L. Perry. 2017. "Public Service Motivation Research: Lessons for Practice.” Public Administration Review 77(4): 529-542.

CRH. 2013. Annual Report and Accounts 2012/13. Calow, Chesterfield, UK: Chesterfield Royal Hospital.

Davis, J.H., F.D. Schoorman and L. Donaldson. 1997. "Toward a Stewardship Theory of Management." Academy of Management Review 22: 20-47.

Dixit, A. 2002. "Incentives and Organizations in the Public Sector: An Interpretative Review." The Journal of Human Resources 37(4): 696-727.

DoH. 2010. Equity and excellence: Liberating the NHS (Cm 7881). London, UK: Department of Health.

DoH. 2012. A simple guide to Payment by Results. Leeds, UK: Payment by Results Team. Department of Health.

Ducharme, M.J., P. Singh and M. Podolsky. 2005. "Exploring the links between performance appraissals and pay satisfaction." Compensation and Benefits Review 37(5): 46-52.

Eijkenaar, F., M. Emmert, M. Scheppach and O. Schöffski. 2013. "Effects of pay for performance in health care: A systematic review of systematic reviews." Health Policy 110: 115-130.

Eldenburg, L. and R. Krishnan. 2003. "Public versus private governance: a study of incentives and operational performance." Journal of Accounting and Economics 35: 377-404.

Ellwood, S. and J. Garcia-Lacalle. 2015. "The influence of presence and position of women on the boards of directors: the case of NHS foundation trusts." Journal of Business Ethics 130(1): 69-84.

Ellwood, S. and J. García-Lacalle. 2016. "Examining Audit Committees in the Corporate Governance of Public Bodies.” Public Management Review 18(8): 11381162.

Fleetcroft, R., N. Steel, R. Cookson, S. Walker and A. Howe. 2012. "Incentive payments are not related to expected health gain in the pay for performance scheme for UK primary care: cross-sectional analysis.” BMC Health Services Research 12: 94.

Fornell, C. and D. Larcker. 1981. "Evaluating structural equation models with unobservable variables and measurement error." Journal of Marketing Research 18: 3950 .

French, P.E. and M.C. Emerson. 2014. "Assessing the Variations in Reward Preference for Local Government Employees in Terms of Position, Public Service Motivation, and Public Sector Motivation." Public Performance \& Management Review 37(4): 552-576.

Frey, B.S., F. Homberg and M. Osterloch. 2013. "Organizational Control Systems and Pay-for-Performance in the Public Service.” Organization Studies 34(7): 949-972.

FPH. 2013. Annual Report and Accounts 2012-2013. Frimley, Camberley, UK: Frimley Park Hospital.

Georgellis, Y., E. Iossa and V. Tabvuma. 2011. "Crowding Out Intrinsic Motivation in the Public Sector." Journal of Public Administration Research and Theory 21(3): 473493. 
Gillam, S.J., A.N. Siriwardena and N. Steel. 2012. "Pay-for-Performance in the United Kingdom: Impact of the Quality and Outcomes Framework-A Systematic Review." Annals of Family Medicine 10(5): 461-468.

Hair, J.F., M. Sarstedt, C.M. Ringle and J.A. Mena. 2012. "An assessment of the use of partial least squares structural equation modelling in marketing research." Journal of the Academy. Marketing Science 40: 414-433.

Jobome, G.O. 2006. "Management Pay, Governance and Performance: The Case of Large UK Nonprofits.” Financial Accountability \& Management 22(4): 331-358.

Kim, J. 2010. "Strategic Human Resource Practices: Introducing Alternatives for Organizational Performance Improvement in the Public Sector." Public Administration Review 70(1): 38-49.

Kjeldsen, A.M. 2012. "Dynamics of Public Service Motivation: Attraction and Socialization Effects in the Production and Regulation of Social Services". Paper presented at the 16th Annual Conference of the International Research Society for Public Management, April 11-13, Rome, Italy.

Langbein, L. 2010. "Economics, Public Service Motivation, and Pay for Performance: Complements or Substitutes?" International Public Management Journal 13(1): 9-23.

Le Grand, J. 2010. "Knights and Knaves Return: Public Service Motivation and the Delivery of Public Services." International Public Management Journal 13(1): 56-71.

Lee, Y-J. and V.M. Wilkins. 2011. "More Similarities or More Differences? Comparing Public and Nonprofit Managers' Job Motivations." Public Administration Review 71(1): 45-56.

Lewis, D.E. 2010. "Measurement and Public Service Motivation: New Insights, Old Questions.” International Public Management Journal 13(1): 46-55.

Lord Hutton Report. 2011. Hutton Review of Fair Pay in the public sector: Final Report. London, UK: Information Policy Team.

Mannion, R. and H.T.O. Davies. 2008. "Payment for performance in health care.” BMJ 336: 306-308.

Marsden, D. 2004. "The role of performance-related pay in renegotiating the "effort bargain": the case of the British public service." Industrial and Labor Relations Review 57(3): 350-370.

Markovits Y., A.J. Davis, D. Fay and R. van Dick. 2010. “The Link Between Job Satisfaction and Organizational Commitment: Differences Between Public and Private Sector Employees.” International Public Management Journal 13(2): 177-196.

Monitor. 2010. The NHS Foundation Trust Code of Governance. London, UK: Monitor. Monitor. 2012. Compliance Framework 2012/13. London, UK: Monitor.

Monitor. 2013a. NHS foundation trusts: consolidated accounts 2012/13. London, UK: Monitor.

Monitor. 2013b. NHS Foundation Trust Annual Reporting Manual for 2012/13. London, UK: Monitor.

Moynihan, D.P. 2013. "Does Public Service Motivation Lead to Budget Maximization? Evidence from an Experiment." International Public Management Journal 16(2):179196. 
NEL. 2013. Annual Report and Accounts 2012/13. Ilford, UK: North East London NHS Foundation Trust.

Newton, A.N. 2015. "Executive compensation, organizational performance, and governance quality in the absence of owners." Journal of Corporate Finance 30: 195222.

NTH. 2013. Annual Report and Accounts 2012-2013. Hardwick, Stockton, UK: North Tees and Hartlepool NHS Foundation Trust.

Nunnally, J.C. 1978. Psychometric theory. New York, NY: McGraw Hill.

Ogundeji, Y.K., J.M. Bland and T.A. Sheldon. 2016. "The effectiveness of payment for performance in health care: A meta-analysis and exploration of variation in outcomes." Health Policy 120: 1141-1150.

Perry, J.L., T.A. Engbers and S.Y. Jun. 2009. "Back to the Future? PerformanceRelated Pay, Empirical Research, and the Perils of Persistence." Public Administration Review 69: 39- 51.

Perry, J.L. and L.R. Wise. 1990. "The Motivational Bases of Public Service.” Public Administration Review 50(3): 367-73.

Preyra, C. and G. Pink. 2001. "Balancing incentives in the compensation contracts of nonprofit hospital CEOs.” Journal of Health Economics 20: 509-525.

Ritz, A., G.A. Brewer and O. Neumann. 2016. "Public Service Motivation: A Systematic Literature Review and Outlook." Public Administration Review 76(3), 414426.

Roldán, J. and M. Sánchez-Franco. 2012. "Variance-based structural equation modeling: guidelines for using Partial Least Squares in information systems research." Pp. 193-221 in Research Methodologies, Innovations and Philosophies in Software Systems Engineering and Information Systems, edited by Manuel Mora, Ovsei Gelman, Annette L. Steenkamp and Mahesh Raisinghani. Hershey, PA: IGI Global.

Ryan, A.M., J. Blustein and L.P. Casalino. 2012. "Medicare's Flagship Test Of PayFor-Performance Did Not Spur More Rapid Quality Improvement Among LowPerforming Hospitals." Health Affairs 31(4): 797-805.

Serrano-Cinca, C., Y. Fuertes-Callén and B. Gutiérrez-Nieto. 2007. "Online reporting by banks: a structural modelling approach.” Online Information Review 31(3): 310-332.

Suff, P., P. Reilly, and A. Cox. 2007. Paying for Performance New trends in performance-related pay. Brighton, UK: Institute for Employment Studies.

Van Herck, P., D. De Smedt, L. Annemans, R. Remmen, M.B. Rosenthal and W.

Sermeus. 2010. "Systematic review: Effects, design choices, and context of pay-forperformance in health care." BMC Health Services Research 10: 247-260.

Wæraas, A. and H. Byrkjeflot. 2012. "Public Sector Organizations and Reputation Management: Five Problems.” International Public Management Journal 15(2): 186206.

Weibel, A., K. Rost and M. Osterloh. 2010. "Pay for Performance in the Public Sector-Benefits and (Hidden) Costs." Journal of Public Administration Research and Theory 20(2): 387-412. 
Wright, B. E. and R.K. Christensen. 2010. "Public Service Motivation: A Test of the Job Attraction-Selection-Attrition Model." International Public Management Journal 13(2): 155-176.

Wright, B.E., R.K. Christensen and S.K. Pandey. 2013. "Measuring Public Service Motivation: Exploring the Equivalence of Existing Global Measures." International Public Management Journal 16(2): 197-223. 
Figure 1. Model for the remuneration of the boards of directors

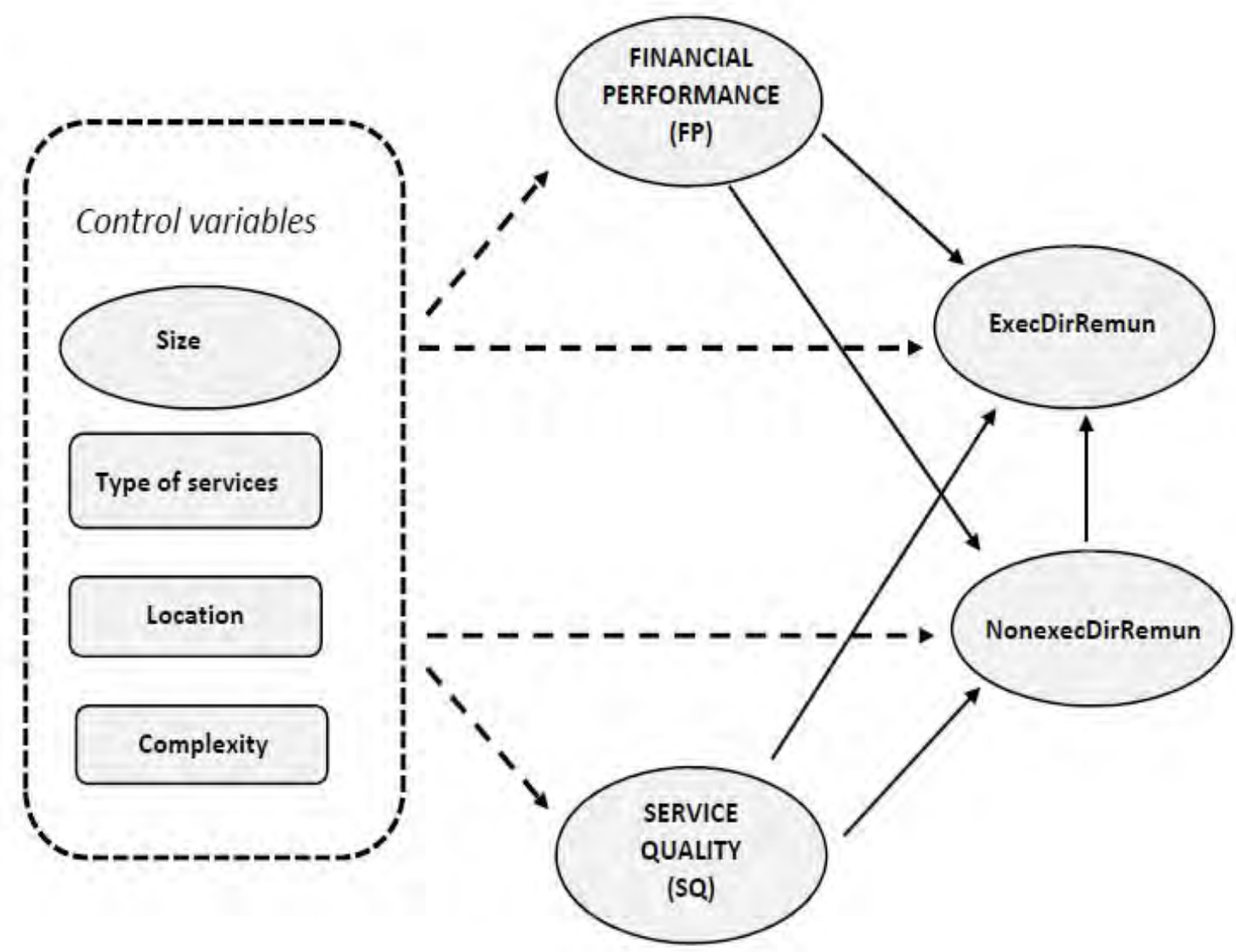

Notes: Rectangles represent variables made up of a single indicator. Ellipses represent "constructs" made up of several items.

Dotted lines represent the relationship between control variables and performance and remuneration. Continuous lines represent the relationship between performance and remuneration as well as the remuneration between non-executives and executives directors. 
Table 1. Descriptive statistics of the items included in the analysis $(\mathrm{N}=130)$

\begin{tabular}{|c|c|c|c|c|c|}
\hline ITEM & Total & Mean & Min & Max & Std Dev \\
\hline Total assets $(£ 000)$ & $25,560,822$ & 196,622 & 11,454 & 858,653 & 133,895 \\
\hline Operating income (£000) & $35,311,917$ & 271,630 & 22,075 & 894,749 & 162,915 \\
\hline Staff & 521,561 & 4,012 & 289 & 12,146 & 2,059 \\
\hline $\begin{array}{l}\text { Type of services (Mental health= } \\
\text { "1")* }\end{array}$ & $38(29 \%)$ & & & & \\
\hline $\begin{array}{c}\text { Location (London and south } \\
\text { east coast = "1")* }\end{array}$ & $25(19 \%)$ & & & & \\
\hline $\begin{array}{l}\text { Complexity } \\
\text { (Non-current assets/Total assets) }\end{array}$ & & 0.74 & 0.28 & 0.93 & 0.10 \\
\hline FRR Q1 2012/13 & & 3.23 & 1 & 5 & 0.85 \\
\hline FRR Q2 2012/13 & & 3.30 & 1 & 5 & 0.85 \\
\hline FRR Q3 2012/13 & & 3.36 & 1 & 5 & 0.93 \\
\hline FRR Q4 2012/13 & & 3.45 & 1 & 5 & 0.92 \\
\hline GRR Q1 2012/13 & & 3.22 & 1 & 4 & 1.06 \\
\hline GRR Q2 2012/13 & & 3.28 & 1 & 4 & 1.04 \\
\hline GRR Q3 2012/13 & & 3.15 & 1 & 4 & 1.14 \\
\hline GRR Q4 2012/13 & & 3.03 & 1 & 4 & 1.11 \\
\hline FRR Q1 2011/12 & & 3.33 & 1 & 5 & 0.85 \\
\hline FRR Q2 2011/12 & & 3.35 & 1 & 5 & 0.85 \\
\hline FRR Q3 2011/12 & & 3.41 & 1 & 5 & 0.82 \\
\hline FRR Q4 2011/12 & & 3.48 & 1 & 5 & 0.78 \\
\hline GRR Q1 2011/12 & & 2.95 & 1 & 4 & 1.06 \\
\hline GRR Q2 2011/12 & & 3.05 & 1 & 4 & 1.01 \\
\hline GRR Q3 2011/12 & & 3.04 & 1 & 4 & 1.07 \\
\hline GRR Q4 2011/12 & & 3.14 & 1 & 4 & 1.03 \\
\hline meanExecExp & & 158,543 & 65,500 & 319,000 & 40,160 \\
\hline relatExecExp & & 3.84 & 1.56 & 7.50 & 1.00 \\
\hline meanNonexecExp & & 20,046 & 11,500 & 35,500 & 3,923 \\
\hline relatNonexecExp & & 0.49 & 0.21 & 1.06 & 0.11 \\
\hline $\begin{array}{l}\text { Exec directors' expenses } \\
(£ 000)^{* *}\end{array}$ & 128,404 & 988 & 422 & 1,903 & 282 \\
\hline $\begin{array}{l}\text { Non-Exec directors' expenses } \\
(£ 000)^{* *}\end{array}$ & 17,162 & 132 & 70 & 234 & 25 \\
\hline
\end{tabular}

Notes: Figures for the year 2012/13, except for FRR and GRR presented also for 2011/12 (N=122).

* The data included in the table are the number of FTs with "1" (and \% of "1" over total).

** Not included in the analyses. Provided for information purposes. 
Table 2. Review of the remuneration section in the annual reports (2012/13)

\begin{tabular}{|l|c|c|}
\hline 1) Remuneration policy (N=140) & n & \% \\
\hline Benchmark + performance appraisal & 58 & 41.4 \\
Benchmark & 20 & 14.3 \\
Performance appraisal & 24 & 17.2 \\
No information & 38 & 27.1 \\
\hline 2) Statement about PRP (N=140) & & \\
\hline Yes, with explicit reference to a PRP scheme & 18 & 12.9 \\
Yes, but explicitly indicates that no PRP scheme has been adopted & 56 & 40.0 \\
No statement about PRP & 66 & 47.1 \\
\hline 3) Bonus column in the remuneration table $(\mathbf{N}=\mathbf{1 3 9 *})$ & 26 & 18.7 \\
\hline 4) Amount reported in the bonus column $(\mathbf{N}=\mathbf{2 6})$ & & \\
\hline Some amount reported & 9 & \\
Total amount of bonuses reported & $£ 354,000^{* *}$ & \\
\hline
\end{tabular}

Notes: *The table of one FT was illegible and, thus, excluded from the analysis.

** $£ 174,000$ corresponding to the Clinical Excellence Award Program. 
Table 3. Measurement model (Model 1)

\begin{tabular}{|c|c|c|c|c|c|}
\hline Factor & Indicator & $\begin{array}{c}\text { Factors } \\
\text { loadings } \\
(\lambda)\end{array}$ & $\begin{array}{l}\text { Cronbach's } \\
\text { Alpha }\end{array}$ & $\begin{array}{c}\text { Composite } \\
\text { Reliability } \\
\text { Index (CRI) }\end{array}$ & $\begin{array}{c}\text { Average } \\
\text { Variance } \\
\text { Extracted } \\
\text { (AVE) }\end{array}$ \\
\hline Size & $\begin{array}{l}\text { Total assets } \\
\text { Total Income } \\
\text { Staff }\end{array}$ & $\begin{array}{l}0.9491 \\
0.9923 \\
0.9687\end{array}$ & 0.9690 & 0.9796 & 0.9413 \\
\hline FP & $\begin{array}{l}\text { FRR Q1 } \\
\text { FRR Q2 } \\
\text { FRR Q3 } \\
\text { FRR Q4 }\end{array}$ & $\begin{array}{l}0.9414 \\
0.9549 \\
0.9561 \\
0.9119\end{array}$ & 0.9570 & 0.9688 & 0.8859 \\
\hline SQ & $\begin{array}{l}\text { GRR Q1 } \\
\text { GRR Q2 } \\
\text { GRR Q3 } \\
\text { GRR Q4 }\end{array}$ & $\begin{array}{l}0.8214 \\
0.8993 \\
0.8964 \\
0.8515\end{array}$ & 0.8913 & 0.9241 & 0.7530 \\
\hline ExecDirRemun & $\begin{array}{l}\text { meanExecExp } \\
\text { relatExecExp }\end{array}$ & $\begin{array}{l}0.9804 \\
0.9786\end{array}$ & 0.9578 & 0.9793 & 0.9595 \\
\hline NonexecDirRemun & $\begin{array}{l}\text { meanNonexecExp } \\
\text { relatNonexecExp }\end{array}$ & $\begin{array}{l}0.9612 \\
0.9766\end{array}$ & 0.9358 & 0.9684 & 0.9388 \\
\hline
\end{tabular}

Note: Information presented only for the constructs made up of two or more items. 
Table 4. Correlations to determine discriminant validity (Model 1)

\begin{tabular}{|l|c|c|c|c|c|c|c|c|}
\hline & Complexity & $\begin{array}{c}\text { ExecDir } \\
\text { Remun }\end{array}$ & FP & Location & $\begin{array}{c}\text { NonExec } \\
\text { DirRemun }\end{array}$ & SQ & Size & Type \\
\hline Complexity & $\mathbf{1}$ & 0 & 0 & 0 & 0 & 0 & 0 & 0 \\
\hline ExecDirRemun & 0.087 & $\mathbf{0 . 9 8 0}$ & 0 & 0 & 0 & 0 & 0 & 0 \\
\hline FP & -0.488 & -0.077 & $\mathbf{0 . 9 4 1}$ & 0 & 0 & 0 & 0 & 0 \\
\hline Location & -0.040 & -0.016 & 0.185 & $\mathbf{1}$ & 0 & 0 & 0 & 0 \\
\hline NonexecDirRemun & 0.067 & 0.191 & -0.037 & -0.134 & $\mathbf{0 . 9 6 9}$ & 0 & 0 & 0 \\
\hline SQ & -0.315 & -0.131 & 0.643 & 0.250 & -0.001 & $\mathbf{0 . 8 6 8}$ & 0 & 0 \\
\hline Size & 0.312 & 0.437 & -0.057 & 0.064 & 0.219 & -0.107 & $\mathbf{0 . 9 7 0}$ & 0 \\
\hline Type of services & -0.240 & 0.031 & 0.288 & 0.073 & 0.138 & 0.400 & -0.199 & $\mathbf{1}$ \\
\hline
\end{tabular}

Note: Figures on the diagonal (bold) are the square root of the AVE values. Off-diagonal figures are the construct correlations 
Table 5. Results of the structural model

\begin{tabular}{|c|c|c|c|c|}
\hline & \multicolumn{2}{|c|}{ Model $1(\mathrm{~N}=130)$} & \multicolumn{2}{|c|}{ Model $2(\mathrm{~N}=122)$} \\
\hline & $\beta$ & $t$-value & $\beta$ & $t$-value \\
\hline Size -> ExecDirRemun & 0.465 & $6.376^{* *}$ & 0.461 & $5.960 * *$ \\
\hline Type of services- $>$ ExecDirRemun & 0.162 & 1.862 & 0.146 & 1.555 \\
\hline Location -> ExecDirRemun & -0.008 & 0.082 & -0.013 & 0.126 \\
\hline Complexity $->$ ExecDirRemun & -0.091 & 0.945 & -0.109 & 1.176 \\
\hline FP -> ExecDirRemun & -0.045 & 0.360 & -0.152 & 1.344 \\
\hline SQ -> ExecDirRemun & -0.144 & 1.391 & -0.001 & 0.014 \\
\hline NonExecDirRemun -> ExecDirRemun & 0.070 & 0.865 & 0.092 & 1.089 \\
\hline Size -> NonexecDirRemun & 0.270 & 1.932 & 0.296 & $2.389 *$ \\
\hline Type of services-> NonexecDirRemun & 0.213 & $2.385 *$ & 0.141 & 1.668 \\
\hline Location -> NonexecDirRemun & -0.161 & $2.113^{*}$ & -0.179 & $2.264 *$ \\
\hline Complexity $->$ NonexecDirRemun & 0.002 & 0.016 & 0.139 & 1.138 \\
\hline FP -> NonexecDirRemun & -0.071 & 0.423 & 0.214 & 1.935 \\
\hline SQ -> NonexecDirRemun & 0.028 & 0.194 & 0.036 & 0.402 \\
\hline Size -> FP & 0.119 & 0.978 & 0.138 & 0.927 \\
\hline Size $->$ SQ & 0.018 & 0.171 & -0.025 & 0.279 \\
\hline Type of services- $>$ FP & 0.188 & $2.311 *$ & 0.252 & $2.740 * *$ \\
\hline Type of services-> SQ & 0.333 & $4.997 * *$ & 0.194 & $2.265 *$ \\
\hline Location -> FP & 0.145 & 1.930 & 0.108 & 1.263 \\
\hline Location -> SQ & 0.215 & $3.892 * *$ & 0.276 & $4.292 * *$ \\
\hline Complexity -> FP & -0.474 & $6.555^{* *}$ & -0.348 & $2.637 * *$ \\
\hline Complexity $->$ SQ & -0.232 & $2.863 * *$ & -0.127 & 1.274 \\
\hline $\mathrm{R}^{2}$ for ExecDirRemun & 0.236 & & 0.228 & \\
\hline $\mathrm{R}^{2}$ for NonexecDirRemun & 0.113 & & 0.191 & \\
\hline $\mathrm{R}^{2}$ for $\mathrm{FP}$ & 0.306 & & 0.216 & \\
\hline $\mathrm{R}^{2}$ for $\mathrm{SQ}$ & 0.258 & & 0.151 & \\
\hline $\mathrm{Q}^{2}$ for ExecDirRemun & 0.227 & & 0.194 & \\
\hline $\mathrm{Q}^{2}$ for NonexecDirRemun & 0.104 & & 0.197 & \\
\hline $\mathrm{Q}^{2}$ for $\mathrm{FP}$ & 0.266 & & 0.180 & \\
\hline $\mathrm{Q}^{2}$ for $\mathrm{SQ}$ & 0.188 & & 0.100 & \\
\hline
\end{tabular}

Note: ** significant at the 0.01 level; * significant at the 0.05 level. 